\title{
A ambas orillas del atlántico. Geografías de hogar y diáspora en aUtoras AFRODESCENDIENTES
}

Autora: Mar Gallego.

Oviedo: KRK Ediciones, 2016.

\author{
Marta Sofía López \\ marta-sofia.lopez@unileon.es \\ Universidad de León - España
}

“¿Y si el 'hogar' [home] no fuese un lugar, sino un nexo de historias?” (Eshun, 2005: 128) La pregunta retórica que se plantea Ekow Eshun en su texto Black Gold of the Sun. Searching for Home in England and Africa (2005) apunta a una experiencia de (des)ubicación emblemática de nuestro mundo globalizado, en el que las fronteras se diluyen y se refuerzan, se defienden con muros o se ven fácilmente atravesadas por el impacto de las nuevas tecnologías, en el que las identidades dependen menos de las raíces que de las rutas existenciales, intelectuales o emocionales que construimos a lo largo de nuestras vidas, en un proceso de negociación constante con la historia, con la memoria individual y colectiva, con las múltiples geografías de la migración y con los lenguajes infinitos de la experiencia.

La identidad, argumenta Stuart Hall "es siempre en parte una narrativa, siempre en parte una especie de representación [...] La identidad no es algo que se forme afuera y sobre lo que luego contemos historias. Es lo que nos narramos a nosotros mismos" (Hall, 1987: 49) Desde muy diferentes ámbitos filosóficos, críticos o disciplinarios, la narratividad ha ido adquiriendo nuevas valencias legitimadoras desde hace algunas décadas, en el contexto de este mundo transnacional, global y postmoderno del siglo XXI. En su magnífico libro The Ethics of Identity (2007), Kwame Anthony Appiah propone la narratividad como el factor decisivo para el reconocimiento de nuestra humanidad común en un paisaje post-ilustrado y cosmopolita:

"El cosmopolitanismo imagina un mundo en el que las personas y las novelas y la música y las películas y las filosofías viajan entre diferentes lugares en los que se entienden de formas diferentes, porque las personas son diferentes y sus diferencias se aceptan gustosamente. El cosmopolitanismo es posible porque puede existir una conversación sobre ideas y objetivos compartidos. Pero lo que hace posible esa conversación no es siempre una "cultura" común, ni siquiera, como los viejos humanistas imaginaban, porque existan principios o valores universales [...] Lo que funciona en el encuentro con otros seres humanos, a pesar de barreras como el tiempo, el espacio o la experiencia, es enormemente variado. Por lo que se refiere a las historias (desde los relatos épicos hasta formas modernas como la novela o el cine), es la capacidad de seguir una 
narrativa y conjurar un mundo: y resulta que en todos los sitios hay personas dispuestas a hacer esto. Esta es la epistemología moral que hace posible el cosmopolitanismo" (Appiah, 2007: 258).

Si me he permitido incorporar una cita tan extensa es porque creo que explica muy bien tanto el propósito como los logros del libro más reciente de la Dra. Mar Gallego, A ambas orillas del Atlántico. Geografías de hogar y diáspora en autoras afrodescendientes (Oviedo: KRK, 2016), incluido en la imprescindible colección "Alternativas." Y no solo de la autora del ensayo, sino también de las cuatro escritoras a cuyas obras dedica sus análisis detallados en la segunda parte del libro. Agnès Agboton (Benín/España), Mónica Carrillo (Perú/Estados Unidos), Eulalia Bernard (Costa Rica) y Fatou Diome (Senegal/Francia) son creadoras que han contribuido significativamente a esa gran revolución cultural mediante la que, en palabras de Stuart Hall, "los márgenes se han insertado en la representación" (Hall, 1997a: $34)$.

Las memorias silenciadas por la historiografía oficial, las identidades tradicionalmente deslegitimadas en razón de su género, su raza, clase social u orientación sexual, entre otros posibles factores, están desvelando, gracias a su acceso a la auto-representación, las múltiples fallas del proyecto de la modernidad concebida según los patrones de la Ilustración europea.

Y para dar cuenta de la magnitud y la relevancia de las intervenciones artísticas y literarias producidas por mujeres afrodescendientes en el eje del Atlántico Negro, la Dra. Mar Gallego no duda en valerse de los más complejos discursos críticos tanto como de datos o estadísticas oficiales, en utilizar herramientas analíticas típicas de la sociología, la teoría literaria, los estudios culturales o el pensamiento feminista, y ponerlas al servicio de una vocación de justicia social que demandan a voz en grito las autoras a las que estudia, como portavoces de una legión de "condenadas de la tierra".

Desde distintos géneros literarios (el cuento, la novela, la poesía o la autobiografía) estas autoras proponen una riqueza de autodefiniciones construidas a partir de la conciencia diaspórica, de sus tránsitos entre lenguas, sociedades y culturas diversas, de su arraigo en la memoria colectiva de la negritud y de su negociación como mujeres con concepciones hegemónicas y unívocas de la identidad, de la nación, del género o la raza.

La primera parte del libro, conformada en un extenso capítulo introductorio, se destina así a tejer un marco teórico que pueda dar cuenta de las complejas raíces históricas, filosóficas, económicas o discursivas de los múltiples ejes de exclusión que sustentan un orden global profundamente desigual e injusto, apoyado sobre dicotomías que cercenan y mutilan las legítimas expectativas de bienestar y felicidad de millones de seres humanos. Y eso implica un viaje incesante entre el pasado y el presente (del esclavismo a las migraciones contemporáneas, de los “discursos científicos sobre las razas” al debate sobre la ciudadanía), entre lo público y lo privado (de las políticas de estado a la sexualidad), entre lo abstracto de 
las grandes palabras filosóficas ("Otredad" o "hibridez", verbigracia) y la experiencia íntima de la violencia o el poder restaurador del erotismo.

La amplitud de este marco de referencia teórico se ve reflejada en una bibliografía relevante, actualizada y multidisciplinar, cuya presencia se hace visible no solo en la sección correspondiente, sino en la riqueza de matices y perspectivas que continuamente aporta la autora, y de forma particular en la lectura y análisis del corpus artístico de las escritoras tratadas en la parte más puramente filológica del libro.

El capítulo segundo se centra en la obra de Agnès Agboton, una de las voces pioneras de la literatura afrohispánica. El capítulo tercero cruza el Atlántico para explorar la obra de la afroperuana Mónica Carrillo y la afrocostarricense Eulalia Bernard, cuyas creaciones se expresan también prioritariamente en español, aunque a veces utilicen, como también es el caso de Agboton, lenguas no europeas (africanas o criollas). El cuarto capítulo se centra en Fatou Diome, autora de origen senegalés asentada en Francia y en cuya obra más conocida, El vientre del Atlántico (2005), se pone de manifiesto el rico simbolismo de este océano que tanto une y tanto separa África, Europa y América. A pesar de estas barreras geográficas y lingüísticas y de los determinantes históricos y personales que configuran la construcción de la identidad de cada una de ellas, la praxis literaria de estas cuatro mujeres revela un número significativo de concomitancias, reflejo de un empeño común por encontrar un espacio creativo capaz de situar la experiencia de la marginalidad en el centro de la representación, como proponía Stuart Hall.

No obstante, A ambas orillas del Atlántico no es un texto pensado ni escrito para acabar solo en las estanterías de instituciones académicas o sesud@s investigador@s. Es también, en el mejor sentido de la palabra, una obra de divulgación, un término que en absoluto puede contraponerse a "investigación" para quienes nos hemos formado en la filosofía profunda de las "Nuevas Humanidades." La sabiduría ha de estar al servicio de la vida, el conocimiento al servicio de la transformación social, los lenguajes a veces crípticos de la teoría al servicio de la revolución cultural y económica demandada por las escritoras que la Dra. Gallego estudia, representantes a su vez de muchas minorías silenciosas.

Como mujeres, nuestra patria es el mundo entero, una orilla y la otra, un discurso y el otro. Como co-madres, no podemos permitir que nuestros privilegios institucionales y sociales, inaccesibles para muchas, nos hagan olvidar sus existencias precarizadas.

Poner nuestro granito de arena para que este planeta sea el hogar común que anhelamos es nuestra tarea irrenunciable. A ambas orillas del Atlántico no es solo una significativa intervención académica en debates teóricos y políticos que están desgarrando nuestras sociedades: es, sobre todo, un ejercicio de amor y empatía, de escucha atenta y cuidadosa, de reterritorialización de saberes imprescindibles para la re/construcción de una sociedad en la que los valores del mujerismo negro propugnado por Alice Walker se divulguen y se implementen, porque como mujeres estamos "comprometidas con la supervivencia y la integridad de todas las gentes” (Walker, 1984: XI). 


\section{BIBLIOGRAFÍA}

- Walker, Alice (1984): In Search of Our Mother's Gardens. Womanist Prose. Londres: The Women's Press.

- Eshun, Ekow (2005): Black Gold of the Sun. Searching for Home in England and Africa. Londres: Penguin Books.

- Hall, Stuart (1997): “Old and New Identities, Old and New Ethnicities”. En: Anthony B. King (ed.): Culture, Globalization and the World System. Contemporary Conditions for the Representation of Identity. Minneapolis, MN: University of Minnesota Press, pp. 41-68. . (1997a): "The Global and the Local: Globalization and Ethnicity”. En: Anthony D. King (ed.): Culture, Globlization and the World-system. London: Macmillan, pp. 19-38.

- Appiah, Kwame Anthony (2007): The Ethics of Identity. Princeton: Princeton University Press. 